\title{
Structure of Hydroxyproline-arabinoside from Tobacco Cells
}

\author{
Yukio AkiYama and Kunio Katō \\ Central Research Institute, The Japan Tobacco \& Salt Public Corporation, \\ 6-2 Umegaoka, Midori-ku, Yokohama 227
}

Received July 15, 1976

\begin{abstract}
The hydroxyprolyl tri and tetraarabinosides were isolated from a cell wall preparation of cultured tobacco cells by alkali hydrolysis, gel filtration and ion-exchange chromatography. The structures of the two hydroxyproline-arabinosides (Ara 3 -Hyp and Ara ${ }_{4}-\mathrm{Hyp}$ ) were determined by analysis of controlled Smith-degradation products, and measurements of PMR

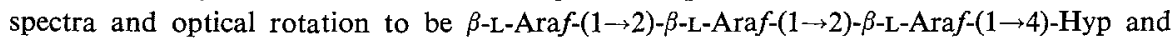

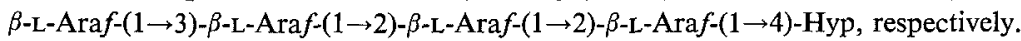

Primary cell walls of plants contain hydroxyproline-rich glycoproteins that are characterized by a short side chain consisting of arabinose bound to the hydroxyl group of hydroxyprolyl residues. ${ }^{1,2)}$ A series of four hydroxyproline-arabinosides (Ara-Hyp, $\mathrm{Ara}_{2}$ Hyp, $\mathrm{Ara}_{3}$-Hyp and $\mathrm{Ara}_{4}$-Hyp) have so far been reported as important fragments of glycoproteins of this kind. ${ }^{2)}$ In our previous paper, ${ }^{3)} \mathrm{Ara}_{3}$-Hyp and $\mathrm{Ara}_{4}$-Hyp were isolated from a cell wall preparation of suspensioncultured tobacco cells. The linkage of the oligoarabinosides to the protein moiety was examined by the standard methylation analytical procedure. In this paper, the structures of these oligoarabinosides were determined by analysis of controlled Smith-degradation products and measurements of PMR spectra and optical rotation.

\section{MATERIALS AND METHODS}

The preparation of samples (B-2, B-3, and B 4 ) and analytical methods were as described previously, ${ }^{3)}$ unless otherwise stated.

Aminex chromatography. Aminex ion-exchange chromatography was performed with hydrochloric acid as eluant instead of $0.01 \mathrm{M}$ acetic acid. The column was eluted with a $\mathrm{pH}$ gradient produced in a two-chambered vessel: the mixing chamber contained $200 \mathrm{ml}$ of water

Abbreviations: Hyp, hydroxyproline; Araf, arabinofuranose; GLC, gas-liquid chromatography; PMR, proton magnetic resonance. and the reservoir $200 \mathrm{ml}$ of $0.2 \mathrm{~N}$ hydrochloric acid. Each fraction was individually neutralized with $0.1 \mathrm{~N}$ sodium hydroxide, and desalted on a column $(100 \times$ $1.6 \mathrm{~cm}$ ) of Sephadex G-15.

Controlled Smith-degradation. A $48 \mathrm{mg}$ sample of B-2 was oxidized with $0.02 \mathrm{M}$ sodium metaperiodate (eight-fold excess) for $96 \mathrm{hr}$ at $4^{\circ} \mathrm{C}$ in the dark, and periodate consumption was estimated by measurement of absorbance at $223 \mathrm{~nm}$. Excess periodate was then destroyed by adding ethylene glycol, and the reaction mixture was reduced with sodium borohydride $(150 \mathrm{mg})$ for $24 \mathrm{hr}$ at $4^{\circ} \mathrm{C}$ in the dark. The excess borohydride was then decomposed by adding acetic acid and the resulting substance was applied to the above Sephadex G-15 column. The desalted solution was evaporated to dryness and the residue was hydrolyzed with $0.1 \mathrm{~N}$ hydrochloric acid for $24 \mathrm{hr}$ at room temperature. In a preliminary experiment, it was found that the $O$ glycosidic bond in the hydroxyproline-arabinosides was not split under such mild acidic conditions. The hydrolyzate was then neutralized with $0.1 \mathrm{~N}$ sodium hydroxide and desalted by gel filtration. The hydrolysis products recovered in the eluate were finally lyophilized and submitted to the methylation analysis.

The determination of anomeric configuration. The anomeric configuration was determined by PMR spectrometry and by estimation of optical rotation.

The PMR spectra were recorded on a JEOL model JNM-PS-100 spectrometer with $\mathrm{D}_{2} \mathrm{O}$ as the solvent at $23^{\circ} \mathrm{C}$. Chemical shifts were measured using tetramethyl silane as external standard.

The optical rotation was measured on a JASCO model DIP-181 polarimeter.

\section{RESULTS AND DISCUSSION}

Most of cell wall Hyp was released upon 
hydrolysis with saturated barium hydroxide, and acid hydrolysis of this alkali extract gave a recovery of $98 \%$ of Hyp contained in the initial cell wall preparation. Three hydroxyprolinearabinoside fractions (B-2, B-3 and B-4) were obtained from alkali extract of cultured tobacco cell walls. They were $\mathrm{Ara}_{4}-\mathrm{Hyp}, \mathrm{Ara}_{4}$ $\mathrm{Hyp}+\mathrm{Ara}_{3}-\mathrm{Hyp}$, and $\mathrm{Ara}_{3}-\mathrm{Hyp}$ as described previously. ${ }^{3)}$

The standard methylation analytical procedure showed that B-2 ( Ara $_{4}$-Hyp) contained terminal, 1,2-linked and 1,3-linked L-arabinofuranosyl residues in a molar ratio of $1: 2: 1$. On the other hand, B-4 (Ara 3 -Hyp) contained these residues in a ratio of $1: 2: 0 .{ }^{3}$ From these results, there is only one possible sequence of residues in B-4 triarabinoside, but for B-2 tetraarabinoside three possible sequences must be considered.

To investigate the sequence of B-2 tetraarabinoside, B-2 ( Ara $_{4}$-Hyp) was oxidized with sodium metaperiodate, reduced, and then hydrolyzed with mild acid (controlled Smithdegradation). The consumption of $\mathrm{IO}_{4}^{-}$was $0.23 \mu$ mole per $1 \mu$ mole of arabinofuranose. Ten $\mathrm{mg}$ of controlled Smith-degraded B-2 was methylated and subjected to GLC analysis as partially methylated alditol acetates. The results of GLC analysis are shown in Table I,

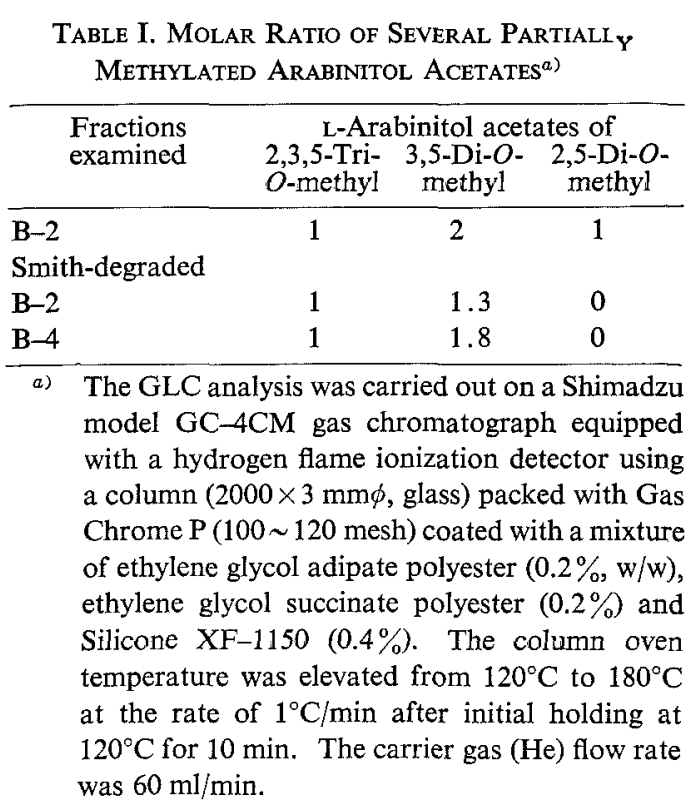

in which the disappearance of the peak corresponding to 2,5-di- $O$-methyl-L-arabinitol triacetates indicates that the terminal L-arabinofuranosyl residue is attached to the next one by a $1 \rightarrow 3 O$-glycosidic bond, since it is known that neither 1,2-linked nor 1,3-linked Larabinofuranosyl residue is degraded upon periodate oxidation. The molar ratio of the peak of 3,5-di- $O$-methyl-L-arabinitol triacetates to 2,3,5-tri- $O$-methyl-L-arabinitol diacetates (1.3) is smaller than expected (2.0). Probably, the two reducing process with sodium borohydride effected the yield, for the reaction velocity is remarkably decreased below $\mathrm{pH} 9.5$.

Secondly, the anomeric configuration of the hydroxyproline-arabinosides was examined.

The results of measurement of PMR are shown in Table II. Capon and Thacker ${ }^{4}$ measured the PMR spectra of $\alpha$ - and $\beta$-methyl glucosides of L-arabinofuranose. They reported that the coupling constants $\left(J_{1,2}\right)$ of $\alpha$ - and $\beta$-derivatives were $1.0 \mathrm{~Hz}$ and $4.0 \mathrm{~Hz}$, respectively. As shown in Table II, the coupling constant of the anomeric proton of the arabinosides is about $4.0 \mathrm{~Hz}$, showing that these arabinosides are $\beta$-anomers.

Table II. Chemical Shifts ( $\delta$ ) and Coupling CONSTANT $\left(J_{1,2}\right)$ OF THE ANOMERIC HYDROGEN ATOMS

\begin{tabular}{ccc}
\hline Fractions examined $\left.^{a}\right)$ & $\delta(\mathrm{ppm})$ & $J_{1,2}(\mathrm{~Hz})$ \\
\hline B-2 & 5.09 & 4.3 \\
B-3 & 5.06 & 4.0 \\
B-4 & 5.04 & 3.7 \\
$\alpha-\mathrm{L}-$ Ara $f$ & 5.07 & 1.5 \\
\hline a) The concentrations were $20 \mathrm{mg} / 0.5 \mathrm{ml} \mathrm{D}_{2} \mathrm{O}$.
\end{tabular}

TABle III. Optical Rotation of HYDROXYPROLINE-ARABINOSIES ${ }^{a}$ )

\begin{tabular}{ccc}
\hline Fractions examined & {$[\alpha]_{\mathrm{D}}^{23}$} & $c$ \\
\hline B-2 & +36.4 & 0.48 \\
B-3 & +73.6 & 0.53 \\
B-4 & +78.4 & 0.35 \\
trans-4-Hydroxy- & -76.3 & 1.0 \\
L-proline & +98.2 & 1.0 \\
$\alpha$-L-Araf & \\
\hline
\end{tabular}

a) The optical rotation was measured with a JASCO model DIP-181 polarimeter with micro cell $(3 \phi \times 100 \mathrm{~mm})$ using $\mathrm{H}_{2} \mathrm{O}$ as solvent. 
Optical rotation was also employed to determine the anomeric configuration of the oligosaccharides. The results are shown in Table III. Arabinans containing $\alpha$-type linkages generally show negative optical rotation, ${ }^{5,8}$ but as shown in Table III, positive values were observed in these hydroxyproline-arabinosides.

From the results described above, it is concluded that the structure of $\mathrm{Ara}_{3}-\mathrm{Hyp}$ and Ara $_{4}$-Hyp from cell wall preparation of cultured tobacco cells was as follows: $\beta$-L-Araf$(1 \rightarrow 2)-\beta$-L-Araf $-(1 \rightarrow 2)-\beta$-L-Ara $f-(1 \rightarrow 4)-$ Hyp and $\beta$-L-Araf- $(1 \rightarrow 3)-\beta$-L-Araf-( $1 \rightarrow 2)-\beta$-L-Araf-
$(1 \rightarrow 2)-\beta$-L-Araf-(1 $\rightarrow 4)$-Hyp, respectively.

\section{REFERENCES}

1) D. T. A. Lamport, Annu. Rev. Plant Physiol., 21, 235 (1970).

2) D. T. A. Lamport and D. H. Miller, Plant Physiol., 48, 454 (1971).

3) Y. Akiyama and K. Katô, Agric. Biol. Chem., 41, in press.

4) B. Capon and D. Thacker, Proc. Chem. Soc., 369 (1964).

5) S. Karácsonyi, R. Toman, F. Janečeck and M. Kubačková, Carbohyd. Res., 44, 285 (1975).

6) O. Larm, O. Theandar and P. Aman, Acta Chem. Scand., Ser. B, 29, 1011 (1975). 